\title{
AN APPLICATION OF AHP USING NON-ADDITIVE WEIGHT IN INFRASTRUCTURE PLANNING
}

\author{
Shin-ei Takano \\ Graduate School of Engineering, Hokkaido University \\ Kitaku Kita 13 Nishi 8, Sapporo, Hokkaido, 060-8628, Japan \\ shey@eng.hokudai.ac.jp
}

\section{Introduction}

A purpose of infrastructure planning is to make a public decision composed of various people. Therefore, it is necessary to consider the diversity of decision making deliberately, compared with individual case. In addition, the decision has a strong social influence force, and future generations are affected. In infrastructure planning, further examinations are necessary, even if an alternative evaluation is judged a superior one as the total average score is high. Because there is a possibility that the evaluation from a factor is extremely low and it may become an important problem. The other way, there is a possibility that even if the total average score is low, the evaluation from a factor is extremely high and a reexamination of this alternative brings about a good result.

\section{Formulation of the evaluation method using fuzzy measure}

In this study, an evaluation method using fuzzy measure is used in order to solve these problems. In this method, the alternative weight from evaluation factors is interpreted as degree of explanation. Then, maxi-max evaluation (MM evaluation) and maxi-min evaluation ( $\mathrm{MN}$ evaluation) are calculated by using possibility measure and necessity measure:((3),(4)) These indexes are evaluations considered from advantage and disadvantage view points. In addition, in this study the average evaluation ( $\mathrm{N}$ evaluation) with a meaning which is almost similar to normal evaluation is formulated.(5)

Degree of explanation

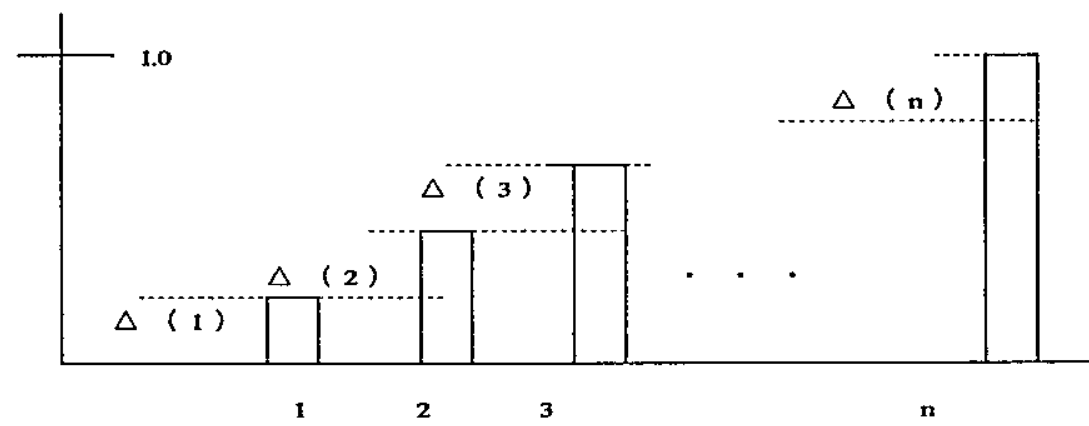

No. of evaluation factors arranged in ascending order of degree of explanation

Fig.1 Degree of explanation and $\Delta(i)$

$$
\begin{aligned}
\left(A-\lambda_{\max } \cdot I\right) \cdot W= & 0--(1) \\
& \max \left(w_{1}\right)=1--\cdots(2) \\
M M(i)= & \sum_{j=I}^{n} \Delta(j) \cdot \max f(i, k)--(3) \\
M N(i)= & \sum_{j=1}^{n} \Delta(j) \cdot \min f(i, k)--(4)
\end{aligned}
$$

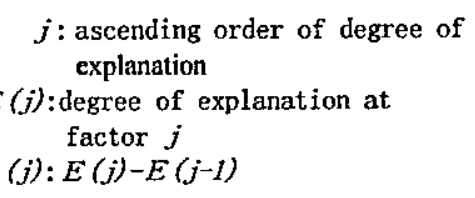




$$
N(i)=\sum_{j=1}^{n} \Delta(j) \cdot \text { me a } n \quad f(i, k)--(5)
$$

$f(i, k)$ : alternative weight from each evaluation factor

Applications to a underground passageway problem and a Shinkansen station problem

The evaluation method is applied to actual infrastructure planning examples of an underground passageway network problem and a Shinkansen station location problem. In an underground passageway network problem, 14 alternatives in Sapporo city are evaluated. The evaluation factors consist of effective utilization of underground facilities, public facilities connection, commercial buildings connection, business facilities connection, a formation of the city axis.(Fig.2) In Shinkansen station problem, seven alternatives are evaluated from eight evaluation factors and it is unique that weights of the evaluation factors are calculated from the result of a questionnairing. By these examples, it is shown that in this method the diversity of evaluations can be analyzed which is difficult in normal method, and the usefulness is verified.

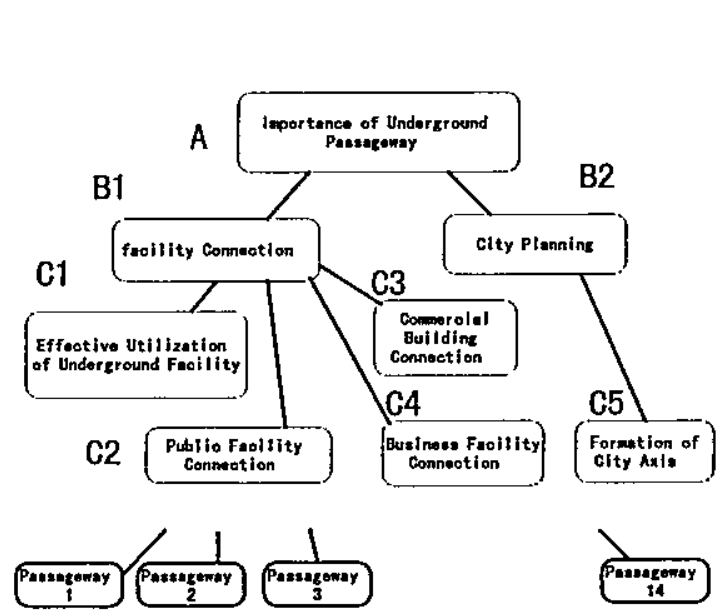

Table 1 Estimnted Result for a Underground Passage Problem

\begin{tabular}{|c|c|c|c|c|c|c|}
\hline & \multicolumn{2}{|c|}{ MMVntis } & \multicolumn{2}{|c|}{ N Valie } & \multicolumn{2}{|c|}{ MNVilto } \\
\hline & Volue & Ruk & Valus & Rnak & Volue & Rmak \\
\hline Prence 1 & $a 748$ & 11 & 0.357 & 14 & $a 2 x$ & 12 \\
\hline Thenge 2 & a748 & 11 & 0389 & 13 & 2200 & 12 \\
\hline Dimere 3 & $a 70$ & 10 & 0.459 & 31 & $0 . x D$ & $\pi$ \\
\hline Finged 4 & a821 & 8 & 0.670 & 8 & $a G(x)$ & 4 \\
\hline howes & $a 7 \pi$ & 9 & 0.544 & 9 & $a, 4(x)$ & 10 \\
\hline Inwonge 6 & o.nss & 3 & $\alpha \mathrm{REn}$ & 1 & 0.723 & 1 \\
\hline Themego 7 & 0,900 & 1 & $a 7 s y$ & 2 & 0,522 & 5 \\
\hline Inemge $B$ & 0.900 & 1 & a720 & 4 & 0.444 & 8 \\
\hline nomeen 9 & 0.850 & 4 & a $74 t$ & 3 & $a \times x$ & 2 \\
\hline thenes 10 & $0.8 \times 0$ & 7 & arriz & 7 & 0.458 & 7 \\
\hline 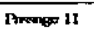 & $0.8 \times 0$ & 7 & D.st & 8 & 0422 & 9 \\
\hline תrempar 12 & 0.624 & 14 & 0.524 & 10 & 0.644 & 6 \\
\hline Panders 1.3 & o.n4 & 13 & $0.4 \times 0$ & 12 & a.xox & 12 \\
\hline Nimes 14 & 0.843 & 5 & $0.71 \pi$ & 5 & $a s 93$ & 4 \\
\hline
\end{tabular}

Fig.2 Underground Passageway Problem
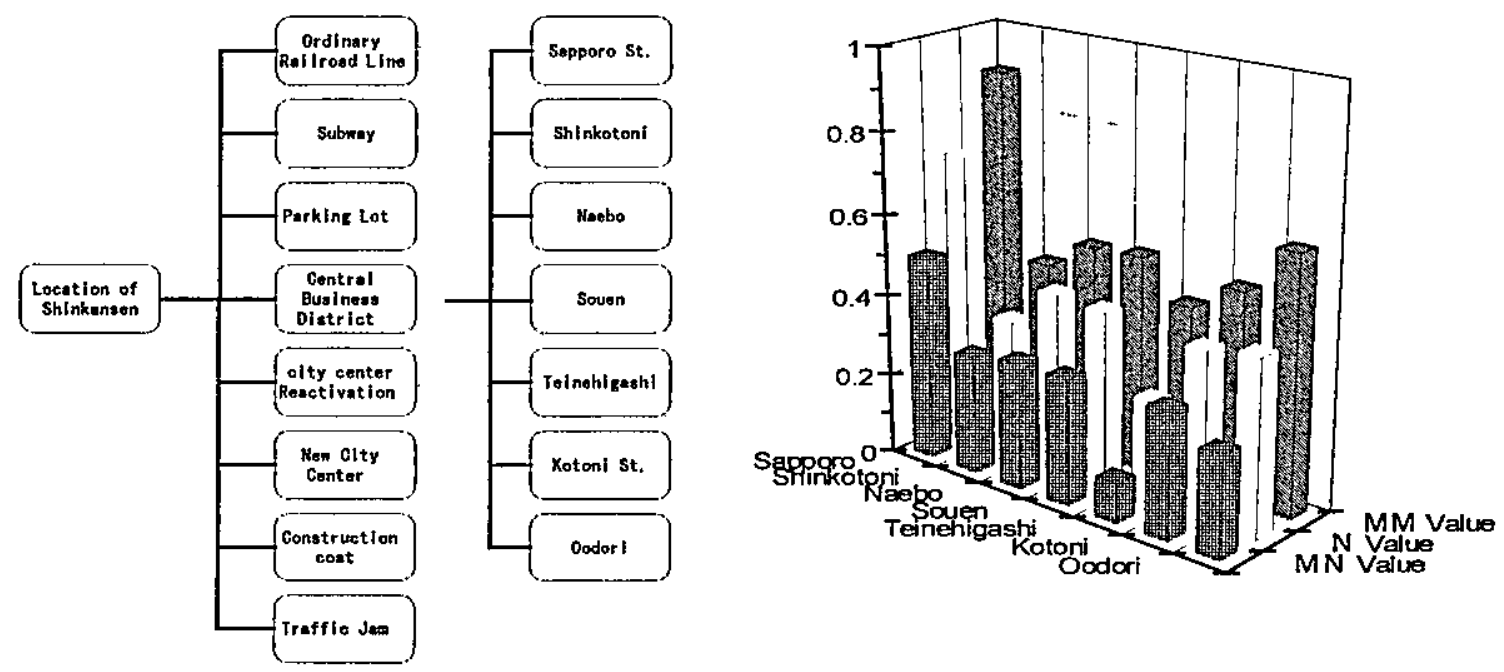

Fig.3 Shinkansen Station Location Problem Fig.4 Estimated Result for Shinkansen Problem 